\title{
Recuperación e posta en produción de terras abandonadas: a visión do sector vacún leiteiro de Galicia como demandantes no mercado de terras
}

Recibido: 30 maio 2014 / Aceptado: 7 novembro 2014

(C) IBADER- Universidade de Santiago de Compostela 2014

\begin{abstract}
Resumo Este traballo busca caracterizar aos usuarios potenciais das terras que actualmente se atopan en situación de abandono ou infrautilización en Galicia. O sector vacún leiteiro constitúe o núcleo básico do sector agrario galego polo que coñecer a súa opinión como demandantes de terra é unha prioridade para poder establecer un plan de mobilidade de terras. A través da aplicación dunha variante da metodoloxía Delphi comprobouse que dende o sector existe un interese por conseguir máis terra e poder aumentar así a base territorial das explotacións e, en consecuencia, a súa capacidade produtiva. A falta de información tanto técnica como lexislativa relativa aos instrumentos que poden axudar á mobilización de terras e o seu funcionamento, quedou presente en moitos dos xuízos emitidos polo panel de expertos consultados para este traballo, polo que este constituiría o primeiro paso cara a consecución dunha mobilidade efectiva de terras.
\end{abstract}

Palabras clave Abandono de terras, cooperativas agrarias, método Delphi, mobilidade de terras.

Lidia Osorio Castelao · Eduardo José Corbelle Rico · Francisco José Ónega López

Laboratorio do Territorio, Escola Politécnica Superir, Universidade de Santiago de Compostela. Campus Universitario s/n, 27002-

Lugo (España).

Tel: 982823292

E-mail: lidia.osorio@rai.usc.es
Abstract This paper aims to identify potential users for some of the land currently abandoned in Galicia. We focused mainly on dairy farmers and cooperatives, as these constitute today the core of the agricultural sector in the region and should play a significant role in an eventual plan for the mobilization of abandoned land. A Delphi expert panel, formed by technicians working in cooperatives, showed considerable interest on the part of the dairy farming sector to increase the amount of land managed and, therefore, their production capacity. We could also detect a somewhat worrying lack of knowledge regarding matters associated to territorial planning and land management instruments that should be addressed in the first place in a near future.

Keywords Delphi method, farmer cooperatives, land abandonment, land mobility.

\section{Introdución}

A segunda metade do século $X X$ supuxo para o sector agrario da Europa occidental o inicio dun proceso dual de marxinalización nalgunhas localizacións e de forte especialización e intensificación noutras, un proceso gobernado por factores económicos, medioambientais, políticos, sociais, culturais e, moi especialmente, os relacionados coa estrutura do parcelario e o tamaño das explotacións (Brouwer et al., 1997). A agricultura e o medio rural galego non foron unha excepción e tamén sufriron, nun período relativamente curto de tempo e en boa medida desde a integración de España na CEE en 1986, transformacións considerables (Sineiro García, 2008). O apurado proceso de reestruturación que padeceron as explotacións caracterizouse por unha banda pola crecente tendencia á especialización e polo incremento do tamaño dunha parte de elas, e pola outra, polo abandono simultáneo da maioría das unidades de pequena dimensión (Sineiro García et al., 2004). Tense suxerido que este continuo peche de explotacións non levou parello unha redistribución da propiedade a través do mercado de terras, co resultado de limitar, de facto, a superficie dispoñible para 
as explotacións que permanecen en activo (López Iglesias, 1996), se ben traballos máis recentes apuntan a que nas áreas de Galicia cun sector agrario máis activo a superficie agrícola utilizada non só non se reduciu senón que incluso se incrementou desde 1985 en adiante (Corbelle Rico \& Crecente Maseda, 2014).

As explotacións de vacún de leite e carne constitúen o núcleo básico do sector agrario en Galicia, tanto dende o punto de vista económico, como social e territorial, e supoñen preto do $50 \%$ do número total de explotacións con terras existentes en Galicia (INE, 2012). A distribución é desigual entre provincias, de xeito que o groso do sector se concentra nas provincias de A Coruña e Lugo. A situación do sector, non obstante, dista de ser desafogada dado que a progresiva intensificación do sistema situou a boa parte das explotacións nunha considerable vulnerabilidade respecto das variacións nos prezos de mercado dos insumos nos que se sustenta a produción (combustible, agroquímicos, alimentos concentrados) ou do seu produto principal, o leite. Neste contexto, comezan a ser frecuentes as voces que propoñen que un incremento da superficie xestionada polas explotacións podería axudar a superar parte destes problemas pola vía de reducir a dependencia de fontes de alimentación externas para o gando (Lorenzana et al., 2010). A Comisión Europea (2013) cifra o custe dos alimentos comprados nun $57,24 \%$ do custe total de funcionamento das explotacións de gando vacún leiteiro de Galicia (152 €/t de leite).

Son varias as iniciativas que tratan de incentivar a mobilidade do mercado de terras para, entre outros obxectivos, mellorar a situación das explotacións agrarias en Galicia. Nomeadamente, a Lei 6/2011 de mobilidade de terras $^{1}$ pretende fomentar a mobilidade a través do funcionamento do Banco de Terras de Galicia. Neste contexto, un grupo de organizacións relacionadas co sector agrario en Galicia decidiron iniciar en 2013 o proxecto MobilízaTe, que ten como obxectivo a mobilización produtiva de superficies potencialmente aproveitables por explotacións agrarias existentes ou de nova creación. O alcance do proxecto, que aínda se atopa nunha fase de definición, vai máis alá do problema da viabilidade das explotacións, e ten implicacións para o mantemento do tecido social e produtivo nas áreas de interior de Galicia, ou para a redución do risco de incendios forestais. As organizacións integrantes do proxecto no momento de escribir este traballo son a Fundación Juana de Vega, a Axencia Galega de Desenvolvemento Rural (a través do Banco de Terras de Galicia), as cooperativas: Cooperativa Agraria Provincial de A Coruña, Cogasar (Sarria), Os Irmandiños (Ribadeo), Melisanto (Melide) e Seragro (Ames), as explotacións gandeiras: Finca A Devesa S.L. (Ponteceso) e Herdanza S.L. (Mesía), a Caixa Rural e o grupo de investigación Laboratorio do Territorio (LaboraTe) da Universidade de Santiago de Compostela.

O obxectivo deste traballo é explorar a percepción que o sector de vacún de leite ten sobre a posibilidade de incorporar á produción terras en estado de abandono, moi probablemente afastadas dos principais puntos de produción, para reducir a súa dependencia dos alimentos concentrados. En particular, interesa coñecer cales son as opinións do sector vacún en Galicia sobre a mobilidade do mercado de terras, dende a súa posición de demandantes hipotéticos, así como sobre a posibilidade de recuperar terras abandonadas; e poder definir deste xeito os criterios necesarios para satisfacer dita demanda e identificar fórmulas ou propostas para conseguir mobilizar a terra. Se os investigadores coñecen de antemán estes factores, será máis doado buscar terras que actualmente se atopan en situación de abandono ou infrautilización en Galicia que satisfagan ditas necesidades e establecer un plan de mobilización produtiva de terras como unha utilidade directa e concreta para os beneficiarios potenciais das terras.

\section{Metodoloxía}

A metodoloxía empregada neste traballo consistiu na aplicación dunha variante do método Delphi a un panel de expertos formado por técnicos e responsables de cooperativas gandeiras.

\section{O método Delphi}

O método Delphi é unha técnica para producir opinións de grupo. O xuízo en grupo presenta unha serie de vantaxes en comparación coas opinións xeradas de xeito individual, destacando especialmente que o grupo dispón de máis recursos (información, coñecementos e experiencias) que aportar en conxunto. Unha das técnicas máis habituais consiste na discusión cara a cara, situando nun mesmo espazo físico a un grupo de expertos para intercambiar información e chegar a unha decisión final en grupo. Porén, a interacción directa entre os participantes constitúe unha das fortalezas e ao mesmo tempo unha das debilidades deste tipo de procesos.

O método Delphi foi concibido para tratar de aproveitar os aspectos positivos dos procesos de discusión grupal ao tempo que se minimizan os seus aspectos negativos e se permite a participación de membros xeograficamente dispersos (Rowe \& Wright, 1999). Desde o punto de vista operativo, o método consiste en tratar de obter o consenso máis fidedigno dun grupo de expertos mediante o uso dunha serie de cuestionarios intercalados con retroalimentación de información controlada (Dalkey \& Helmer, 1963). Dado que a palabra consenso pode ter un sentido demasiado restritivo, algúns autores propoñen que sería máis axeitado falar de opinión grupal, de aí que se poida caracterizar a Delphi como un método de estruturación dun proceso de comunicación grupal que é efectivo á hora de permitir que un grupo de individuos, coma un todo, faga fronte a un problema complexo (Linstone \& Turoff, 2002). O método conta con considerable aceptación na comunidade científica e técnica e o uso desta técnica é relativamente habitual na investigación (Gupta \& Clarke, 1996; Landeta, 2006). 
As características básicas que definen o método Delphi son (Dalkey \& Helmer, 1963; Landeta, 1999):

a) Proceso iterativo. A través de sucesivas roldas de cuestionarios, os participantes tenden a converxer, finalizando o proceso no momento en que as opinións se estabilizan. Esta forma de proceder ofrece ao experto a oportunidade reflexionar ou se se dá o caso, de cambiar as súas opinións ou xuízos sen sentirse coaccionado polo "que dirán" o resto de integrantes no grupo.

b) Anonimato dos participantes. Implica que ningún membro do grupo coñeza as respostas individuais do resto de participantes, eliminando deste xeito as causas que impulsan as inhibición dos participantes e permitindo que cada individuo teña a oportunidade de expresar a súa opinión ou xuízo sen presións sociais. Isto conséguese grazas aos cuestionarios, conectando directamente aos expertos cos investigadores que forman o grupo coordinador do Delphi .

c) Feedback ou retroalimentación controlado. Subminístrase entre cada iteración e transmítese sempre a posición xeral do grupo en cada momento do proceso (medidas de tendencia central e de dispersión das respostas do grupo na rolda anterior) e frecuentemente, achegas ou suxestións significativas orixinadas polo propio panel de expertos e información adicional procedente do equipo coordinador, sempre que se considere pertinente. Opcionalmente pódense anexar as respostas do experto nesa rolda.

d) Resposta estatística de grupo. Permite unha análise cuantitativa e a interpretación dos datos. Nos casos nos que o grupo de expertos teña que realizar unha estimación numérica, a resposta ven caracterizada pola mediana das respostas individuais. A resposta estatística de grupo garante que todas as achegas ou opinións se teñan en conta na opinión final de grupo e reduce a presión cara a conformidade.

\section{Selección do panel de expertos}

Os expertos constitúen o núcleo do método, xa que eles son os encargados de emitir os xuízos que constituirán a resposta final do método. Para a selección dos expertos é imprescindible que estes poidan aportar información obxectiva e subxectiva sobre o tema a estudar e que teñan unha situación e recursos persoais que lles posibiliten contribuír positivamente á consecución do fin que motivou a iniciación do método Delphi (Landeta, 1999). Estas razóns, entre outras, motivaron a selección de técnicos e responsables de cooperativas agrarias como os integrantes principais do panel de expertos consultados. As cooperativas agrarias xogan un papel fundamental na vertebración do sector agroalimentario e no desenvolvemento rural, tanto no ámbito territorial, como no social e económico: o número de cooperativas agrarias rexistradas en Galicia ascende a 351(IGE, 2012), e segundo o informe de Jordán Rodríguez \& Babío Arcay (2010) as cooperativas de primeiro e de segundo grao vinculadas ao complexo agrogandeiro representan preto dos dous terzos da facturación cooperativa total en Galicia (Facturación total en Galicia: $217470688 €$ ) e achegan máis da metade do valor engadido de todo o movemento cooperativo (Valor engadido total en Galicia: 172068298,3 $€)$.

Para a formación do panel de expertos partimos da selección inicial das cooperativas relacionadas co sector de vacún leiteiro en tanto que, por abranguer un gran número de explotacións, deberían ser coñecedores en profundidade do sector e das inquietudes dos seus socios. Deste xeito, o grupo de expertos estivo formado por 15 técnicos, xerentes, directores, asesores, xefes de sección ou técnicos de xestión de cooperativas, máis outras 4 persoas ligadas á Consellería do Medio Rural e Mar, ao Centro de Investigacións Agrarias de Mabegondo e ao Banco de Terras de Galicia. Do total de 19 membros do panel, 12 eran homes e 7 mulleres. Deste xeito, o número de participantes no panel sitúase no rango recomendado pola maioría de manuais, que suxiren desde un mínimo de 7 ata un máximo de 30 ou 35 persoas (Dalkey, 1969; Delbecq et al., 1989; Gordon, 2009; Ruiz Olabuénaga, 2007), ou entre 10 e 15 cando o grupo é homoxéneo, como é este caso (Skulmoski \& Hartman, 2007).

\section{Desenvolvemento do proceso}

Para motivar aos participantes no panel a permanecer activos e completar todas as roldas dun estudo Delphi, é importante que se sintan parte do grupo, que son capaces de aportar xuízos de valor e axudar a examinar o problema. Se o grupo coordinador invita a participar aos expertos de forma individual, a posibilidade dunha maior participación é máis forte (Stitt-Gohdes \& Crews, 2004), polo que se realizou un primeiro contacto mediante chamada telefónica a cada experto co fin de informar sobre o proceso e preguntar se estarían dispostos a participar nel. Unha vez asegurada a súa colaboración, os expertos recibiron certa información a través do correo electrónico: unha breve descrición do estudo, os obxectivos, a metodoloxía empregada e a promesa do anonimato.

A continuación, deron comezo un total de catro roldas de cuestionarios, que seguiron o proceso representado na Figura 1. Cada cuestionario estaba composto por 4, 5, 3 e 2 preguntas respectivamente. Os expertos dispoñían de 5 días para devolver completo o cuestionario, coa excepción da segunda rolda na que tiveron 4 días. O tempo entre roldas, é dicir o tempo que transcorría entre que remataba o prazo de entrega do cuestionario ata que recibían o seguinte, foi de 3 días, salvo a terceira rolda que tivo unha duración de 85 días. A participación dos expertos foi diminuíndo conforme pasaban as roldas, acadando un $84 \%$ na primeira rolda, un $74 \%$ na segunda, un $58 \%$ na terceira e un $47 \%$ na derradeira.

Nos cuestionarios empregados ao longo do proceso fóronse incluíndo preguntas relacionadas cos requirimentos que deberían cumprir as parcelas para ser aproveitadas, xunto con outras que trataban de ir máis aló destes aspectos concretos para coñecer de modo máis xeral a opinión dos expertos nos aspectos relacionados con este traballo. 


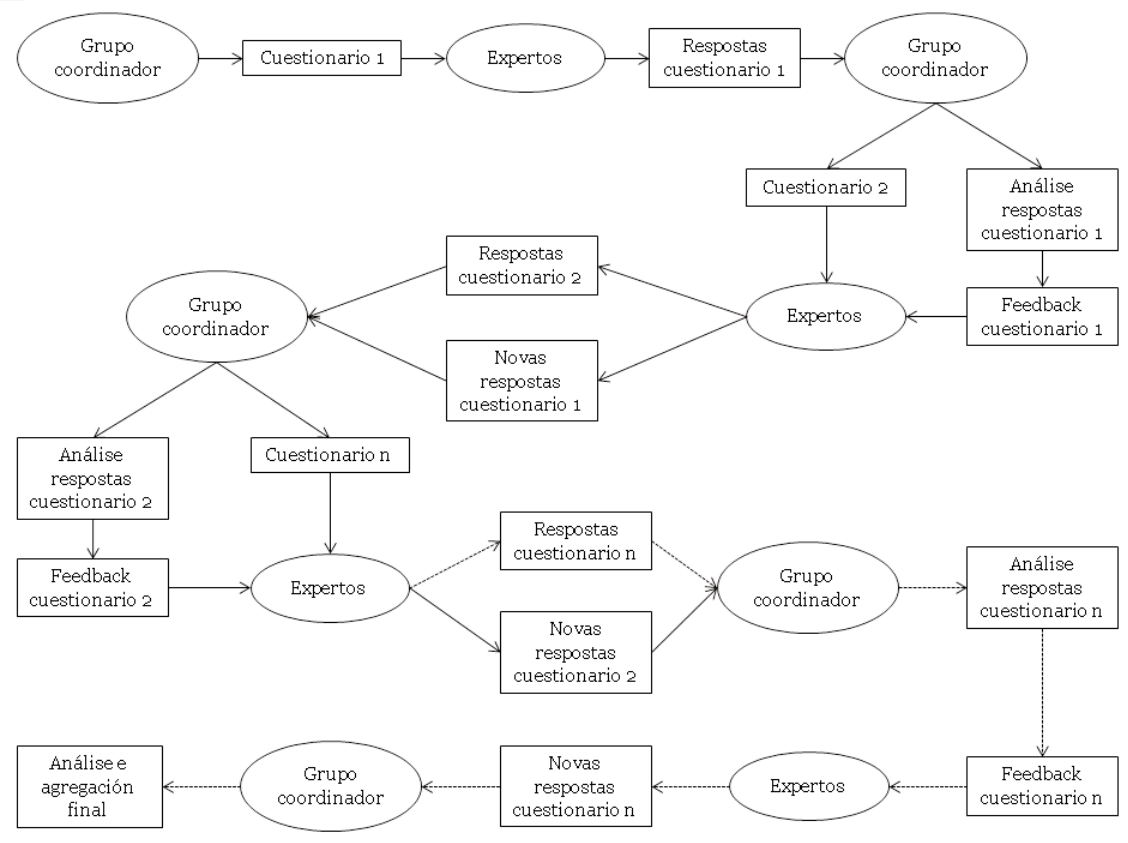

Figura 1.- Esquema global do proceso Delphi

\section{Resultados}

\section{A recuperación de terra abandonada}

Nunha das primeiras preguntas chave preguntouse aos expertos sobre a posibilidade de utilizar bolsas de terras que actualmente están en situación de infrautilización ou simplemente abandonadas. Foi case unánime a resposta positiva, o que demostra un claro interese do sector por recuperar as terras abandonadas para o cultivo e fomentar así a mobilidade de terras. Un número considerable de expertos avogan pola necesidade de utilizar estas terras. Un experto fai a seguinte reflexión sobre a obrigatoriedade da utilización desas bolsas e menciona que poden constituír unha medida para paliar os incendios forestais, idea tamén mencionada por outro dos expertos:

"Eu non consideraría necesario empregalas [grandes bolsas de terra en Galicia que están abandonadas ou en situación de infrautilización], paréceme máis oportuno dicir que sería obrigatorio. Estamos a comprar forraxes en outras comunidades deixándolles a eles o beneficio, e ao mesmo tempo investindo euros da nosa comunidade para paliar incendios, que na meirande maioría se producen nestas masa de terras non traballadas. O resultado sería polo tanto un dobre beneficio, económico e ambiental o mesmo tempo (experto 7)."

Tan só un dos enquisados opinou que non sería viable a utilización das bolsas de terras abandonadas, acompañando a súa resposta co seguinte razoamento:

"Realmente existe moito terreo sen utilizar ou cun baixo nivel de utilización, pero considero que actualmente non é viable a súa utilización na maior parte dos casos, mentres non se realice unha efectiva ordenación do territorio. Aínda cos prezos de mercado de pensos e combustibles actuais, debido a falta de ordenación do territorio, hoxe para calquera explotación sen terra resulta máis barato a adquisición no exterior que a posibilidade de incrementar a súa base territorial porque non é rendible o traballo da terra nas condicións actuais, é triste pero é así (experto 11)."

\section{As características das terras demandadas}

Os expertos listaron, por orde de importancia, aqueles requirimentos que preferentemente buscarían á hora de acceder ás parcelas identificadas como abandonadas ou infrautilizadas. O requirimento de maior importancia é o tamaño da parcela, seguido da accesibilidade da parcela, da localización da mesma e das características que presente o terreo; mentres que o prezo e a duración do contrato de aluguer son os de menor importancia xa que só foron citadas nunha ocasión respectivamente.

En canto a qué tipo de producións se establecerían nesas bolsas de terra, os expertos tiveron que escoller tres e o resultado da súa selección amósase na figura 2.

Segundo a figura 2, aínda que as "Producións forestais" abranguen un $20 \%$ das producións citadas polos expertos, o conxunto formado por "Cultivos forraxeiros", "Millo" e "Prados, pradarías e pastos" supón un $49 \%$ do total das producións que implantarían os expertos nas bolsas de terra abandonadas ou infrautilizadas.

Co fin de poder determinar unha distancia á que sería posible desprazarse para comezar a producir e unha superficie para a que pagaría a pena, os expertos tiveron que indicar unha combinación de ambas e o resultado foi unha relación lineal do tipo "Area (ha) $=1+0,5$ * distancia $(\mathrm{km})$ ", da que se deriva que por cada $\mathrm{km}$ no que nos afastemos, o panel de expertos considera necesario que a área dispoñible sexa 0,5 ha máis grande. 


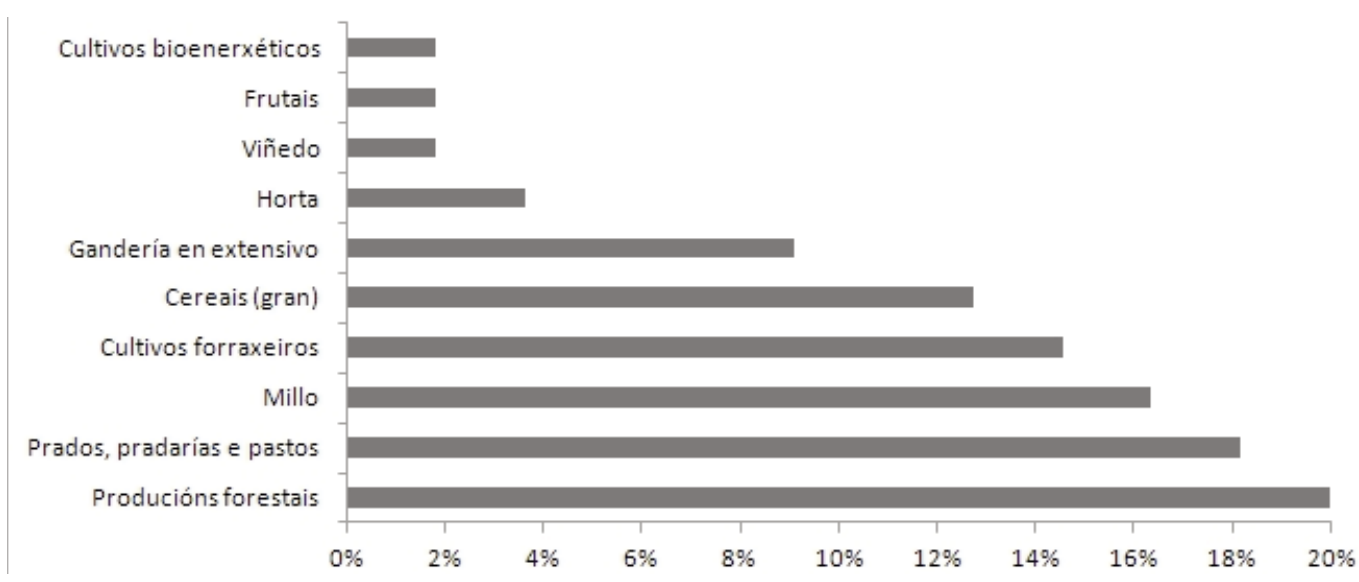

Figura 2.- Tipos de producións que implantarían os expertos nas bolsas de terra identificadas como abandonadas ou infrautilizadas (Nota: estableceuse a diferenciación entre "Millo" e "Prados, pradarías e pastos" porque aínda que ambos son cultivos forraxeiros, a maioría das respostas especificaban estas dúas producións, de xeito que aquel participante que non especificou o cultivo en concreto ou que nomeou un diferente dos dous grupos anteriores, incluíuse no grupo xenérico "Cultivos forraxeiros". No grupo "Cereais (gran)" agrúpanse os cultivos de avea, cebada, centeo e trigo.)

A superficie na que se comezará a nova produción probablemente se compoña de lotes de parcelas próximas entre si, por iso se preguntou ao panel de expertos polo tamaño mínimo que considerarían para unha unidade de cultivo contigua. O valor da mediana obtido para o tamaño mínimo do lote de parcelas requirido para comezar a nova produción é de 1 ha.

Sendo o millo unha das producións máis veces citada para establecer nas bolsas de terra, centrámonos neste cultivo paradeterminar a relación existente entre produtividade, distancia e área. As respostas recibidas do panel axustáronse a un modelo de regresión lineal múltiple do tipo "Produtividade = $\mathrm{f}$ (distancia, área)", obtendo a ecuación "Produtividade $(\mathrm{kg} \mathrm{ms} / \mathrm{ha})=9300+[290 \times$ distancia $(\mathrm{km})]-$ [200 $\times$ area (ha)]". Dito modelo suxire que, para igual área, cada km que nos afastemos requiriría un aumento de produtividade de $290 \mathrm{~kg} \mathrm{~ms} / \mathrm{ha}-a n o ;$ e que para igual distancia, cada ha que aumente a superficie permitiríanos asumir unha perda de produtividade de $200 \mathrm{~kg} \mathrm{~ms} / \mathrm{ha}$-ano.

\section{A ordenación do territorio}

O concepto de ordenación do territorio aparece mencionado en diferentes respostas ao longo das catro roldas de preguntas por diferentes expertos, ben sexa como unha posible medida necesaria para a posta en produción das bolsas de terra ou como un dos motivos (particularmente a súa ausencia) que dificultan a mobilidade de terras en Galicia. Por esta razón foi obxecto dunha consulta específica, que trataba de indagar sobre o grao de coñecemento que tiñan os expertos sobre as medidas ou instrumentos de ordenación do territorio actualmente en vigor. Sorprendentemente, as respostas evidenciaron un grao de coñecemento aceptable para profesionais que non teñen neste ámbito o seu principal campo de actividade, pero menor do que sería desexable para poder utilizar estes mecanismos en favor da viabilidade do sector. Os instrumentos de ordenación máis coñecidos resultaron ser a concentración parcelaria, a aplicación da normativa referente a plantacións forestais en terreos agrícolas (artigo 61 da Lei 7/2012 de montes de Galicia2) e os Plans Xerais de Ordenación Municipal (PXOM). Outras medidas en vigor citadas en só unha ocasión son a aplicación da normativa contra incendios e a figura do Banco de Terras de Galicia. O resto de medidas achegadas son a realizacióndunha correcta caracterización do territorio en canto a usos e aptitudes, a elaboración de mapas de cultivos ou a mellorada xestión comunitaria de terras, que aínda que non se poida definir se están vixentes porque non teñen unha normativa que as avalen, tamén son instrumentos de ordenación do territorio xa que pretenden influír no patrón de utilización territorial de xeito explícito.

Tamén aparecen nomeadas en tres ocasións, como medidas hipotéticas, aquelas focalizadas en penalizar aos propietarios que abandonen as súas propiedades e non faciliten a mobilización de terras, e en premiar aos que si que colaboren, economicamente falando. Un dos expertos comenta o seguinte:

"Ante a pasividade social que conleva o abandono das terras, as medidas válidas só serán aquelas que leven aparelladas a obrigatoriedade ou a penalización (...) (experto 11)".

Outro experto reflexiona sobre a escaso grao de aplicación da normativa vixente:

"Como medidas, penso que aplicando a lexislación vixente xa se faría bastante, sobre todo no que respecta a forestación de terras agrícolas (...), no relativo ao 
cumprimento do plan de usos e cultivos e a unidade mínima de superficie establecido nas zonas de concentración parcelaria (...), no establecido na lexislación en materia urbanística, incluíndo PXOM ou figuras similares e na aposta polo Banco de Terras e outras medidas que fomentan a mobilidade de terras, como as contempladas na Lei de Mobilidade de Terras (...) (experto 18)."

Intentamos profundar entón se os expertos coñecían se nos concellos nos que desempeñan o seu traballo habitual existe algún tipo de plan xeral que delimitase o solo rústico de protección agropecuaria e de protección forestal. A maioría de respostas foron positivas e só dous expertos admitiron que descoñecen o que acontece nalgúns dos concellos nos que desempeñan o seu traballo habitual. Pero este dato de coñecemento por parte dos enquisados resulta enganoso xa que moitos dos concellos que aparecen nomeados nas respostas como que teñen un plan xeral, na realidade non o teñen ${ }^{3}$.

Resulta moi habitual, e de feito pálpase en moitas das respostas, atribuír todo o peso sobre a Administración, á que se considera como o único axente responsable de impulsar a mobilidade de terras. Precisamente para afondar nesta cuestión, e sobre o que os actores directamente implicados (gandeiros e cooperativistas) poden facer neste sentido, situamos o seguinte paquete de cuestións.

\section{Os marcos de negociación posibles}

A seguinte cuestión analizada céntrase en como acceder a esas terras para comezar a mobilizalas, xa que o máis probable é que pertenzan a diferentes propietarios. As solucións propostas polos expertos agrúpanse en catro grupos, sendo o máis maioritario aquel que considera o Banco de Terras como a mellor ferramenta para facilitar e axilizar a mobilidade de terras nesas zonas e levar a cabo os arranxos cos propietarios. Resulta paradoxal que, sendo esta medida a que máis apoio recibe, se perciba nalgunha das respostas unha falta de información e coñecemento do funcionamento do mesmo, especialmente no referente ás garantías que xa ofrece o Banco de Terras en canto a garantir a propiedade, o cobro ou o estado no que se devolven as fincas. En segundo lugar, seguen estando presentes aquelas medidas ideais centradas en premiar dalgún xeito aos propietarios que faciliten o acceso á terra e, por outra banda, crear normativas que obriguen a arrendar daquelas terras que non se están aproveitando adecuadamente.

A creación dunha sociedade de propietarios é o seguintedos medios que algún dos expertos consideran que axudarían a facilitar o acceso á terra. Neste tema, hai opinións contrapostas:

"O ideal sería que [os propietarios] fixeran unha sociedade (...) e así teríamos un só negociador (experto 2)."

“(...) a creación dunha sociedade entre os propietarios podería facilitar a negociación, pero o máis probable e que tamén dilate os prazosao xerar maior burocracia no proceso (...) (experto 14)."

"É moito mellor calquera tipo de solución que ir negociando con cada un dos propietarios (...) (experto 15)."

Preguntamos especificamente pola viabilidade que os membros do panel atribuían á creación da figura dun xestor único, unipersoal ou grupo de traballo, que coordinase as negociacións entre demandantes e ofertantes de terra, e sobre as características principais que debería presentar este coordinador para chegar a bo fin nas negociacións. A posibilidade de que a persoa formase parte do persoal dunha cooperativa non tivo boa acollida entre os membros do panel: aínda que contaría coa vantaxe de coñecer a zona, son moitos os que consideran que unha persoa independente e allea á cooperativa resultaría máis eficaz para evitar a desconfianza dos propietarios ou incluso as reticencias entre aqueles que non formen parte da cooperativa en cuestión. Só un dos enquisados (experto 11) non optou nin por que fose persoal de cooperativa nin alleo, senón que nos devolveu á idea de que o negociador debería ser a propia Administración para evitar a presenza dun intermediario que puidera especular cos terreos e aumentase deste xeito a desconfianza dos propietarios.

En canto ás características principais que debería cumprir, son moitos os que avogan por un perfil negociador antes que técnico, recalcando especialmente que sexa coñecedor da zona (medio rural e persoas). Un experto reflexiona sobre a posibilidade de que sexa un "líder local" o condutor das negociacións e as xestións:

"Creo que un líder local sería o mellor (...), unha persoa coñecida e apreciada polos lugareños e/ou propietarios da zona en cuestión (experto 17)".

\section{Discusión}

Despois de analizar as respostas emitidas polos expertos, é evidente o interese que existe no sector vacún leiteiro por se implicar na mobilización de terras. A existencia de terras aptas para o cultivo que non se están aproveitando para tal fin, incluso nas proximidades de explotacións en activo, tamén é palpable: Giménez Solla et al. (2012) identificaron, nun estudo levado a cabo na Terra Chá, que a superficie de terras potencialmente utilizables no radio actual de actividade das explotacións equivalían ao $1800 \%$ sobre a SAU das explotacións.

Sería interesante poder poñer un número e localizar á cantidade de terra que conta cunha elevada aptitude produtiva e que actualmente está quedando abandonada, para ser conscientes do potencial que se está desaproveitando na nosa comunidade e poder converter as hipóteses plantexadas nas preguntas dos cuestionarios deste estudo en datos reais. Deste xeito, as explotacións poderían valorar a opción de recuperar esas terras para aumentar a súa base territorial e poñer cifras ao custo que levaría implícito dita recuperación. Na liña do Plan Piloto

3: O tipo de plan vixente en cada concello pode consultarse na web mantida de forma conxunta entre a Consellería de Medio Ambiente, Territorio e Infraestruturas, e o Colexio de Arquitectos de Galicia: http://www.planeamentourbanistico.xunta.es. 
Mobilízate, está o traballo realizado por Carballal Fernández (2013) no que se identificaron as superficies en estado de abandono de Galicia que cumpren certos requisitos para a produción forraxeira, previamente establecidos polos participantes no Plan. Estableceuse o millo como referencia para poder fixar os requirimentos mínimos produtivos, xunto cunhas características estruturais en canto a tamaño de parcela e distancia dende os ata as parcelas dende os puntos tomados como referencia, para que o desprazamento ata esas zonas sexa compensado coa colleita. A estimación realizada cuantifica en Galicia case 33600 ha que se atopan na actualidade en estado de abandono pero que son aptas para o cultivo do millo (produtividade mínima de 9 toneladas de MS/ha), que teñen unha superficie mínima continua de 2 ha e nun radio de 2 $\mathrm{Km}$ hai máis de 50 ha, ademais de atoparse a unha distancia máxima de $100 \mathrm{~km}$ aos puntos de orixe. Este dato non é máis que unha estimación, no propio estudo póñense de manifesto unha serie de factores que poden modificar o resultado tanto para aumentar esa cifra ou para reducila, pero é suficiente para pensar que a posta en produción desas hectáreas tería un valor que actualmente se está perdendo. Constitúe un punto de partida para futuros traballo xa que localiza aquelas zonas cun alto interese para o sector vacún leiteiro e impulsa a idea de que a mobilización produtiva de terras é posible.

A falta de información identificada nalgunhas das cuestións relacionadas coa ordenación territorial resulta moi importante xa que se gandeiros e propietarios descoñecen o marco legal, dificilmente poderán esixir o seu cumprimento. Este sería un dos puntos nos que habería que insistir para acadar o cambio desexado e integrar desta maneira aos gandeiros/propietarios na cadea da mobilidade de terras como os actores máis importantes. Este descoñecemento afecta de maneira especial á actividade e procedementos do Banco de Terras de Galicia, dado que a súa potencialidade para converterse en actor central na mobilización do mercado de terras en Galicia se ve coartada pola súa escasa presenza e difusión sobre o terreo.

\section{Conclusións}

Podemos dicir que por parte do panel de expertos seleccionado, e en consecuencia, do sector vacún leiteiro de Galicia, existe un interese por conseguir máis terra e aumentar deste xeito a base territorial das explotacións, estando dispostos a participar como un elo máis na cadea da mobilización de terras. Pero coa vontade non é suficiente e despois de analizar as respostas dos diferentes cuestionarios, pálpase unha falta de información tanto técnica como lexislativa nos técnicos do sector, polo que un proceso de dinamización sobre os instrumentos que poden axudar á mobilización de terras e o seu funcionamento, xunto con charlas informativas considéranse prioritarios para alcanzar o primeiro paso cara o cambio.

A presentación dun proxecto fiable, é dicir, coñecer en profundidade o proxecto que se vai levar a cabo, tamén resulta prioritario para que os propietarios das bolsas de terra abandonadas ou infrautilizadas coñezan de primeira man os obxectivos do mesmo e se sintan como os actores principais que son, xa que sen eles todo o proceso non sería posible. Pódese dicir que antes que mobilizar terras, hai que mobilizar ás persoas (Coímbra, 2011). Pero a cuestión é que para acceder a estas bolsas de terra e ter a capacidade de xestionalas, hai que estar avalados por unha boa organización. Baseándose nunha forma de traballo na que participen e se impliquen todos os actores da cadea (Administración autonómica, administracións e entidades locais, gandeiros, propietarios, cooperativas, investigadores, ...) conseguiremos unha mobilización efectiva das terras. Por todos é coñecido que a capacidade de acción e reacción actuando de forma conxunta e organizada é moito maior, por iso se debe tratar de fomentalo.

Agradecementos Os autores agradecen a todos os participantes que formaron parte do panel de expertos no método Delphi e especialmente a Ruth Rodríguez Ferreiros, da Asociación galega de Cooperativas Agroalimentarias (AGACA), por axudar na selección dos técnicos de cooperativas.

\section{Bibliografía}

Brouwer, F., Baldock, D., Godeschalk, F.\& Beaufoy, G. (1997). Marginalisation of agricultural land in Europe. En Livestock systems in European rural development (pp. 21-31). Nafplio, Greece. Dispoñible en: http://www.macaulay.ac.uk/livestocksystems/nafplio/procee dings/brouwer.htm [29 maio,2014]

Carballal Fernández, M. (2013). Mobilización productiva de terras: organización da demanda e da oferta. Estudo de caso para a posta en produción de 1000 ha en Galicia.TFM, Universidade de Santiago de Compostela.

Coímbra, E. (2011). Land management grounded in social soil. Galician land banking in context. Sociología, problemas e prácticas, 66, 135-155.

Comisión Europea. (2013). EU Dairy farms - Report 2012 based on FADN data. Brussels.

Corbelle Rico, E. J.\& Crecente Maseda, R. (2014). Urbanización, forestación e abandono. Cambios recentes na paisaxe de Galicia. Revista Galega de Economía, 22(2).

Dalkey, N. C. (1969). The Delphi method: An experimental study of group opinion. Dispoñible en: http://www.rand.org/content/dam/rand/pubs/research_mem oranda/RM5888/RM5888.pdf [29 maio, 2014]

Dalkey, N. C.\& Helmer, O. (1963). An experimental application of the Delphi method to the use of experts. Management Science, 9(3), 458-467. doi: $10.1287 / \mathrm{mnsc}$.9.3.458

Delbecq, A. L., Van de Ven, A. H.\& Gustafson, D. H. (1989). Técnicas grupales para la planeación. Mexico: Editorial Trillas, S. A. 
Giménez Solla, M., Corbelle Rico, E. J.\& Ónega López, F. J. (2012). A utilización do espazo polas explotacións gandeiras. Estudio na comarca de Terra Chá, Lugo. En R. Crecente Maseda \& U. Fra Paleo (Eds.), Territorios a examen. Trabajos de ordenación territorial (pp. 57-69). Santiago de Compostela: Servicio de Publicacións e Intercambio Científico. Universidade de Santiago de Compostela.

Gordon, T. J. (2009). Delphi. En J. C. Glenn \& T. J. Gordon (Eds.), Futures Research Methodology Version 3.0.

Gupta, U. G.\& Clarke, R. E. (1996). Theory and applications of the Delphi technique: A bibliography (1975-1994). Technological Forecasting and Social Change, 53(2), 185-211. doi:10.1016/S0040-1625(96)00094-7

Instituto Galego de Estatística. (2012). Dispoñible en: http://www.ige.eu

Instituto Nacional de Estadística. (2012). Censo Agrario de 2009. Dispoñible en: http://www.ine.es/

Jordán Rodríguez, M.\& Babío Arcay, M. R. (2010). Cooperativas de Galicia. Informe de síntese. 2007 (Xunta de Galicia, p. 133).

Landeta, J. (1999). El método Delphi. Una técnica de previsión para la incertidumbre (p. 223). Barcelona: Editorial Ariel, S.A.

Landeta, J. (2006). Current validity of the Delphi method in social sciences. Technological Forecasting and Social Change, 73(5), 467-482. doi:10.1016/j.techfore.2005.09.002

Linstone, H. A.\& Turoff, M. (Eds.). (2002). The Delphi Method. Techniques and applications.Dispoñible en: http://is.njit.edu/pubs/delphibook/ [29 maio, 2014]

López Iglesias, E. (1996). Movilidad de la tierra y dinámica de las estructuras agrarias en Galicia (p. 525). Madrid: Ministerio de Agricultura, Pesca y Alimentación. Secretaría General Técnica.
Lorenzana Fernández, R., Villada Legaspi, E.\& Ónega López, F. J. (2010). Perspectivas de futuro da estrutura produtiva, a demografía e a utilización do espazo agrario en Galicia. O exemplo do sector lácteo. Cooperación Galega. Caderno de Divulgación Técnica, No 101.

Rowe, G.\& Wright, G. (1999). The Delphi technique as a forecasting tool: issues and analysis. International Journal of Forecasting, 15(4), 353-375. doi:10.1016/S01692070(99)00018-7

Ruiz Olabuénaga, J. I. (2007). Investigación en - de - con el grupo. En Metodología de la investigación cualitativa (pp. 247-276). Bilbao: Universidad de Deusto.

Sineiro García, F. (2008). La integración de la agricultura gallega en la unión europea. Revista Galega de Economía, 17, 1-14.

Sineiro García, F., López Iglesias, E., Lorenzana, R.\& Valdês, B. (2004). La tipología de las explotaciones en función de su viabilidad económica y demográfica; aplicación a las explotaciones de bovino en Galicia. Economía Agraria y Recursos Naturales, 4, 63-85.

Skulmoski, G. J.\& Hartman, F. T. (2007). The Delphi method for graduate research. Journal of Information Technology Education, 6(1), 1-21. doi:10.1.1.151.8144

Stitt-Gohdes, W. L.\& Crews, T. B. (2004). The Delphi technique: a research strategy for career and technical education. Journal of Career and Technical Education, 20(2). Dispoñible en: http://scholar.lib.vt.edu/ejournals/JCTE/v20n2/stitt.html [29 maio, 2014] 